\title{
Undiagnosed diabetes mellitus in rural communities in Sudan: prevalence and risk factors
}

\author{
S.K.M. Noor, ${ }^{7}$ S.O.E. Bushara, ${ }^{7}$ A.A. Sulaiman, ${ }^{2}$ W.M.Y. Elmadhoun ${ }^{3}$ and M.H. Ahmed ${ }^{4}$
}

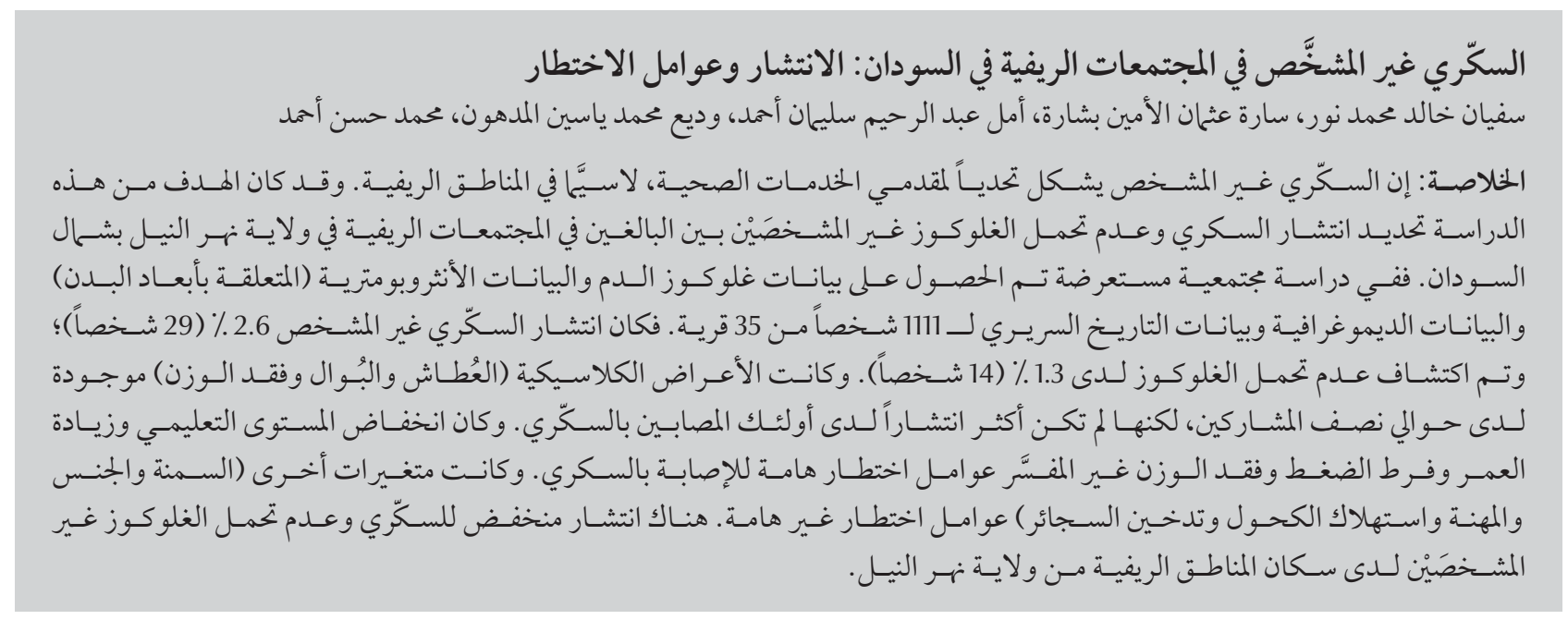

ABSTRACT Undiagnosed diabetes constitutes a challenge for health providers, especially in rural areas. The aim of this study was to determine the prevalence of undiagnosed diabetes mellitus and glucose intolerance among adults in rural communities in River Nile State, north Sudan. In a cross-sectional community-based study, blood glucose, anthropometric, demographic and clinical history data were obtained from 1111 individuals from 35 villages. The prevalence of undiagnosed diabetes was 2.6\% (29 individuals); glucose intolerance was detected in 1.3\% (14 individuals). Classic symptoms (polydipsia, polyuria and weight loss) were present in around half of the participants but were not more prevalent in those with diabetes. Lower educational level, increasing age, hypertension and unexplained weight loss were significant risk factors for diabetes. Other variables (obesity, sex, occupation, alcohol consumption and cigarette smoking) were not significant risk factors. There is a low prevalence of undiagnosed diabetes and glucose intolerance in the rural population of River Nile State.

Diabète non diagnostiqué dans les communautés rurales du Soudan : prévalence et facteurs de risque

RÉSUMÉ Le diabète non diagnostiqué représente un défi pour les prestataires de santé, en particulier dans les zones rurales. L'objectif de la présente étude était de déterminer la prévalence du diabète et de l'intolérance au glucose non diagnostiqués chez des adultes de communautés rurales de l'État du Nil, au nord du Soudan. Dans une étude transversale en communauté, des données glycémiques, anthropométriques, démographiques et les antécédents cliniques ont été obtenus auprès de 1111 résidents de 35 villages. La prévalence du diabète non diagnostiqué était de 2,6 \% (29 personnes) ; I'intolérance au glucose a été dépistée chez 1,3\% (14 personnes). Les symptômes classiques (polydipsie, polyurie et perte de poids) étaient présents chez près de la moitié des participants mais n'étaient pas davantage prévalents chez les personnes atteintes de diabète. Un faible niveau d'études, un âge avancé, une hypertension et une perte de poids inexpliquée étaient des facteurs de risque importants pour le diabète. Des variables comme l'obésité, le sexe, l'emploi, la consommation d'alcool et un tabagisme étaient d'autres facteurs de risque importants. La prévalence du diabète et de l'intolérance au glucose non diagnostiqués était faible dans la population de l'État du Nil.

${ }^{7}$ Department of Medicine; ${ }^{2}$ Department of Community Medicine; ${ }^{3}$ Department of Pathology, Faculty of Medicine and Health Sciences, Nile Valley University, Atbara, Sudan. ${ }^{4}$ Department of Medicine, Milton Keynes Hospital NHS Foundation Trust, Milton Keynes, United Kingdom (Correspondence to M.H. Ahmed: elziber@yahoo.com).

Received: 01/07/14; accepted: 22/01/15 


\section{Introduction}

The prevalence of diabetes mellitus and glycaemia are increasing worldwide, driven both by population growth and by ageing. The Global Burden of Metabolic Risk Factors of Chronic Diseases Collaborating Group estimated the trends of diabetes mellitus prevalence for adults aged 25 years and older in 199 countries and territories (1). This showed that the number of people with diabetes had increased from 153 million in 1980 to 347 million in 2008. The International Diabetes Federation estimates that the number of people with diabetes will increase globally from 366 million in 2011 to 552 million by 2030 in 10 countries (2), and studies from several different countries also predict that the epidemic of diabetes will continue to increase (3-6).

The World Health Organization (WHO) Eastern Mediterranean Region has the highest comparative prevalence of diabetes in the world. For instance, 7 countries in this Region have diabetes prevalence of more than 15\% (Kuwait, Lebanon, Qatar, Saudi Arabia, Bahrain, United Arab Emirates and Egypt), 7 countries have a medium prevalence of 9-12\% (Iraq, Jordan, Oman, Sudan, Syrian Arab Republic, Tunisia and Yemen) while only 6 countries have a prevalence below 9\% (Algeria, Comoros, Djibouti, Mauritania, Morocco and Somalia) (7). Meanwhile, in Africa, diabetes mellitus is estimated to affect around 14 million individuals and this is expected to rise to about 28 million by 2030 (8). The rise has been attributed to lack of physical activity, high carbohydrate intake and ageing populations (9). Importantly, there is an increase in the prevalence in obesity - an important risk factor for type 2 diabetes - in Africa (10). In Sudan, the national prevalence of diabetes in adults is $7.7 \%$ and is expected to reach $10.8 \%$ in 2035 (8).

Diabetes mellitus exerts a significant burden resulting in increased morbidity and mortality, decreased life expectancy and reduced quality of life, as well as loss of income for individuals and nations (11). Early detection and effective treatment delays the onset and reduces the progression of complications $(12,13)$. Most of the studies of diabetes mellitus in Sudan have been institution-based and urban-focused, with few studies made in rural communities (who constitute more than $60 \%$ of the total population). Hence, population-based epidemiological information from both rural and urban populations is essential to understand the whole picture of diabetes in Sudan. This study aimed to determine the prevalence of undiagnosed diabetes mellitus and glucose intolerance and the associated risk factors among a rural population in River Nile State, Sudan.

\section{Methods}

A descriptive cross-sectional community-based study was conducted as a house-to-house survey in May 2013.

\section{Study setting}

River Nile State lies in north Sudan, covering an area of $124000 \mathrm{~m}^{2}$ bordering the capital Khartoum and extending to the borders of Egypt in the north. The total population is about 1250000 people of different ethnic backgrounds, with a dominance of Gaaleen tribes, most of whom are farmers living in rural areas. There are 6 cities in the State and about 350 small villages which have similar demographic characteristics.

\section{Sampling}

Theestimated population of theselected villages was about 100000 . The sample size for the study was determined by assuming the prevalence of diabetes mellitus in the rural population in north Sudan to be $1.7 \%$, as determined by a previous study (14), with a $95 \%$ confidence level and $10 \%$ non-response rate. Accordingly, the calculated sample size for this study was 1100 .
A 2-stage cluster selection technique was used. The 350 villages in the State were clustered into 35 geographical groups, then 35 villages proportional to the number of villages in each locality were randomly selected from the different localities by simple random selection technique. Thereafter, all eligible adults from house-to-house visits who volunteered to participate were included. The total number of participants was 1111. Individuals with the following conditions were excluded from this study: below the age of 18 years, previously diagnosed with diabetes, pregnant or currently taking drugs with a possible impact on glucose metabolism.

\section{Data collection}

The WHO stepwise approach for noncommunicable diseases surveillance was used for data collection. The approach had 3 levels: a questionnaire to gather demographic and behavioural information; physical measurements including anthropometric and blood pressure; and biochemical tests (15).

\section{Questionnaire}

Demographic and clinical data were collected by an interview using a pretested questionnaire. Each participant was questioned about risk factors such as demographics, past medical history, common symptoms of diabetes and family history of diabetes.

\section{Anthropometric measurements}

Anthropometric measurements were taken using standardized techniques and calibrated equipment. Body mass index (BMI) was calculated by the formula: weight in kilograms divided by height in meters squared. BMI < $18.5 \mathrm{~kg} / \mathrm{m}^{2}$ was defined underweight, $18.5-24.9 \mathrm{~kg} / \mathrm{m}^{2}$ as normal, $25-29.9$ $\mathrm{kg} / \mathrm{m}^{2}$ as overweight and $>30 \mathrm{~kg} / \mathrm{m}^{2}$ as obesity (16).

\section{Blood glucose measurement}

A finger-prick capillary blood sample was obtained. Random blood samples were tested for glucose level using a glucometer (Accu-Check Active', Roche 
Diagnostic). Diagnosis of diabetes was based on the American Diabetes Association 2003 criteria (17). An individual with a random glucose $\geq 11.1 \mathrm{mmol} / \mathrm{L}$ $(\geq 200 \mathrm{mg} / \mathrm{dL}$ ) was considered diabetic. Fasting blood glucose tests were done at 08:00 hours, with 8-10 hours overnight fasting for those who had random glucose of $\geq 9.4 \mathrm{mmol} / \mathrm{L}(\geq 170 \mathrm{mg} /$ $\mathrm{dL}$ ). Any individual with fasting blood glucose $\geq 7 \mathrm{mmol} / \mathrm{L}(\geq 126 \mathrm{mg} / \mathrm{dL})$ was considered diabetic. Individuals with random glucose $9.4-11 \mathrm{mmol} / \mathrm{L}$ (170-199 mg/dL) or fasting blood glucose $6.1-6.9 \mathrm{mmol} / \mathrm{L}(110-125$ $\mathrm{mg} / \mathrm{dL}$ ) were considered as cases of impaired glucose tolerance (IGT).

\section{Blood pressure measurement}

Blood pressure was measured with the person in the sitting position using a calibrated portable mercury sphygmomanometer, with appropriate cuff size. The average of 3 readings each taken after 5 minutes rest was recorded. Blood pressure levels were classified according to the criteria of the 7th report of the Joint National Committee on Prevention, Detection, Evaluation and Treatment of High Blood Pressure (18). Normal blood pressure is defined as a systolic blood pressure $<120 \mathrm{mmHg}$ and a diastolic blood pressure $<80 \mathrm{mmHg}$. Prehypertension is defined as a systolic blood pressure $120-139 \mathrm{mmHg}$ and/ or a diastolic blood pressure 80-89 $\mathrm{mmHg}$. Hypertension was defined as a systolic blood pressure $\geq 140 \mathrm{mmHg}$ and/or a diastolic blood pressure $\geq 90$ $\mathrm{mmHg}$

\section{Quality assurance}

House-to-house data collection was performed by trained fieldworkers. The field study team was composed of laboratory technicians, medical students and physicians. All were trained for 3 days on the study procedures by the principle investigator.

\section{Ethical considerations}

Verbal consent was obtained from each participant prior to enrolment.
The following information was given during data collection to ensure they had the information needed to make the informed consent: participation was optional; there would be no penalty for refusal; a complete description of the aims of the study; potential benefits and risks of the study; and assurance of confidentiality of any information given. Any other additional information requested by participants was provided during data collection. All individuals found to have a high blood glucose or any other medical condition were referred to a physician for further management. All information obtained was kept confidential. All patients attended the physician's clinic at the time of study were offered free-of-charge investigations and medications; no additional financial burdens were added to participants. Ethical clearance of the research was obtained from the ethics committee of the Faculty of Medicine at Nile Valley University.

\section{Statistical analysis}

The data generated were coded, validated and analysed using SPSS, version 20. The main variables analysed were age, sex, BMI, blood glucose level, blood pressure and a family history of diabetes mellitus. Pearson chi-squared test was used to test for significance between proportions. $P$-value $<0.05$ was considered statistically significant.

\section{Results}

\section{Demographic characteristics}

A total of 1111 participants were enrolled in this study: 655 (59.0\%) females and $456(41.0 \%)$ males (female to male ratio of $1.5: 1$ ). The sociodemographic characteristics of the participants are displayed in Table 1 . The age range was 18-95 years, with a mean age of 39.3 (standard deviation 16.2) years. Most participants $(69.2 \%)$ were aged 45 years or below. The education profile of the participants showed that $67.8 \%$ had 10 years or less of education.

\section{Clinical profile}

Out of the 1111 subjects tested, 29 (2.6\%) were found to have undiagnosed diabetes mellitus, while 14 (1.3\%) were found to have IGT. The prevalence of most of the common clinical signs and symptoms of diabetes (polydipsia, polyuria and fatigue), were not specific for diabetics, as shown in Table 2. However, unexplained weight loss was a significantly risk factor for diabetes $(P$ $<0.01)$. None of the classic clinical signs of diabetes showed a statistically significant association with glycaemic status. Among the individuals diagnosed with diabetes in this study, 9 (34.6\%) had prehypertension and 17 (65.4\%) had hypertension; none were normotensive.

\section{Factors associated with diabetes mellitus and IGT}

Table 3 shows the relationship between some demographic and clinical risk factors and glycaemic status. Undiagnosed diabetes was found in $22(3.4 \%)$ females and $7(1.5 \%)$ males $(P=0.053)$. The significant risk factors for diabetes were advancing age $(P<0.01)$, lower educational level $(P<0.01)$ and high blood pressure $(P=0.02)$. The prevalence of diabetes was significantly higher in certain tribes (Manasir, Rubatab and Gaaleen), although it should be noted that the participants were mostly from the Gaaleen tribe. The prevalence of diabetes was higher in those with a positive family history of diabetes (3.8\%) than those without a family history (1.9\%) but this was not statistically significant $(P=0.10)$. Occupation, BMI, alcohol consumption and cigarette smoking were also not statistically significant risk factors.

\section{Discussion}

In this first population-based cross-sectional study in rural areas of the north 


\begin{tabular}{|c|c|c|}
\hline \multicolumn{3}{|c|}{$\begin{array}{l}\text { Table } 1 \text { Demographic characteristics of the rural population in River Nile State, } \\
\text { Sudan, } 2013(n=1111)\end{array}$} \\
\hline Variable & No. & $\%$ \\
\hline \multicolumn{3}{|l|}{ Age group (years) } \\
\hline $18-35$ & 535 & 48.3 \\
\hline $36-55$ & 390 & 35.2 \\
\hline $56-75$ & 152 & 13.7 \\
\hline $76-95$ & 31 & 2.8 \\
\hline \multicolumn{3}{|l|}{ Sex } \\
\hline Male & 456 & 41.0 \\
\hline Female & 655 & 59.0 \\
\hline \multicolumn{3}{|l|}{ Educational level } \\
\hline Illiterate & 155 & 14.0 \\
\hline 10 years or less & 786 & 67.8 \\
\hline College and above & 201 & 18.2 \\
\hline \multicolumn{3}{|l|}{ Residence by locality } \\
\hline Ed Damar & 632 & 65.9 \\
\hline Abu Hamad & 225 & 20.3 \\
\hline Berber & 224 & 20.2 \\
\hline \multicolumn{3}{|l|}{ Occupation } \\
\hline Housewife & 504 & 45.4 \\
\hline Self-employed & 181 & 16.3 \\
\hline Employee & 138 & 12.4 \\
\hline Student & 129 & 11.6 \\
\hline Farmer & 100 & 9.0 \\
\hline Unemployed or retired & 12 & 1.1 \\
\hline
\end{tabular}

of Sudan, we were able to measure the prevalence of undiagnosed diabetes mellitus among adults aged 35 years and older. We also determined the prevalence of IGT in this population. The prevalence of undiagnosed diabetes mellitus in our study was $2.6 \%$ and IGT was diagnosed in $1.3 \%$ of the population. This is similar to the prevalence of new cases of diabetes in a population study in north of Sudan in 1996, which was estimated to be around 2.2\% (19). The high prevalence of new cases of diabetes among Danagla tribes in that study was attributed to excess carbohydrate and fat intake. The prevalence of diabetes in our study is similar to that of rural residents in West Africa (2.6\%)
(20). Even though the prevalence of diabetes mellitus in this study is lower than that among Danagla tribes in north Sudan (19), it is comparatively lower than the prevalence seen among urban areas of Sudan (7.7\%) and urban Egypt (20\%) (21,22). Differences observed in diabetes prevalence estimates across rural and urban studies might be due to the sociodemographic and lifestyle differences in the populations studied (23). Furthermore, studies showed that urbanization and economic development are increasing the prevalence of diabetes mellitus by about $40 \%(24,25)$.

The main risk factors for diabetes mellitus and IGT in our study were unexplained weight loss, hypertension, low educational level and older age. The increasing rate of diabetes mellitus with increasing age has been demonstrated in a number of studies $(26,27)$. Interestingly, obesity was not a significant risk factor in this study and this is consistent with studies from Tunisia (28) and Ethiopia (29). This may in part explain why no major difference was noted in the prevalence of new case of diabetes between our study and the earlier study in north Sudan in 1996. However, studies from other countries showed that obesity can be a risk factor for diabetes in rural communities $(26,30)$. The low prevalence of obesity in rural communities in Sudan may be attributed in part to healthy traditional dietary habits together with high levels of physical activity. Most of the cases of diabetes

Table 2 Presence of classic signs/symptoms of diabetes according to glycaemic status among a rural population in River Nile State, Sudan, $2013(n=1111)$

\begin{tabular}{|c|c|c|c|c|c|c|c|c|}
\hline \multirow{3}{*}{$\begin{array}{l}\text { Classic symptoms of } \\
\text { diabetes mellitus }\end{array}$} & \multicolumn{6}{|c|}{ Glycaemic status } & \multicolumn{2}{|c|}{ Statistical analysis } \\
\hline & \multicolumn{2}{|c|}{ Normoglycaemic } & \multicolumn{2}{|c|}{$\begin{array}{l}\text { Impaired glucose } \\
\text { tolerance }^{\mathrm{a}}\end{array}$} & \multicolumn{2}{|c|}{ Diabetes mellitus $^{\mathrm{b}}$} & \multirow[t]{2}{*}{$\chi^{2}$} & \multirow[t]{2}{*}{$P$-value } \\
\hline & No. & $\%$ & No. & $\%$ & No. & $\%$ & & \\
\hline Fatigue & 626 & 96.9 & 5 & 0.8 & 15 & 2.3 & 3.5 & 0.18 \\
\hline Polyuria & 226 & 96.2 & 3 & 1.3 & 6 & 2.6 & 0.0 & 1.0 \\
\hline Polydipsia & 419 & 96.8 & 2 & 0.5 & 12 & 2.8 & 3.7 & 0.16 \\
\hline Weight loss & 250 & 93.6 & 3 & 1.1 & 14 & 5.2 & 9.6 & 0.01 \\
\hline Total & 1068 & 96.1 & 14 & 1.3 & 29 & 2.6 & - & - \\
\hline
\end{tabular}

${ }^{a}$ Random blood glucose $9.4-11 \mathrm{mmol} / \mathrm{L}$ or fasting blood glucose $6.1-6.9 \mathrm{mmol} / \mathrm{L} ;{ }^{b}$ Fasting blood glucose $\geq 7 \mathrm{mmol} / \mathrm{L}$. 


\begin{tabular}{|c|c|c|c|c|c|c|c|c|}
\hline \multirow[t]{2}{*}{ Risk factor } & \multicolumn{2}{|c|}{ Normoglycaemic } & \multicolumn{2}{|c|}{$\mathrm{IGT}^{\mathrm{b}}$} & \multicolumn{2}{|c|}{ Diabetes mellitus ${ }^{c}$} & \multicolumn{2}{|c|}{ Statistical analysis } \\
\hline & No. & $\%$ & No. & $\%$ & No. & $\%$ & $x^{2}$ & $P$-value \\
\hline Total $^{\mathrm{a}}$ & 1068 & 96.1 & 14 & 1.3 & 29 & 2.6 & & \\
\hline \multicolumn{9}{|l|}{ Age group (years) } \\
\hline $18-35$ & 527 & 98.5 & 2 & 0.4 & 6 & 1.1 & \multirow{4}{*}{25.15} & 0.01 \\
\hline $36-55$ & 367 & 94.1 & 10 & 2.6 & 13 & 3.3 & & \\
\hline $56-75$ & 141 & 92.8 & 2 & 1.3 & 9 & 5.9 & & \\
\hline 76-95 & 30 & 96.8 & 0 & 0.0 & 1 & 3.2 & & \\
\hline \multicolumn{9}{|l|}{ Sex } \\
\hline Male & 445 & 97.6 & 4 & 0.9 & 7 & 1.5 & \multirow[t]{2}{*}{4.5} & 0.11 \\
\hline Female & 623 & 95.1 & 10 & 1.5 & 22 & 3.4 & & \\
\hline \multicolumn{9}{|l|}{ Educational level } \\
\hline Illiterate & 143 & 92.3 & 3 & 1.9 & 9 & 5.8 & \multirow[t]{4}{*}{16.87} & 0.01 \\
\hline 10 years or less & 381 & 94.8 & 6 & 1.5 & 15 & 3.7 & & \\
\hline More than 10 years & 340 & 97.7 & 3 & 0.9 & 5 & 1.4 & & \\
\hline College and above & 199 & 99.0 & 2 & 1.0 & 0 & 0.0 & & \\
\hline \multicolumn{9}{|l|}{ Occupation } \\
\hline Housewife & 473 & 93.8 & 9 & 1.8 & 22 & 4.4 & \multirow[t]{6}{*}{17.1} & 0.25 \\
\hline Self-employed & 177 & 97.8 & 1 & 0.6 & 3 & 1.6 & & \\
\hline Employee & 133 & 96.4 & 2 & 1.4 & 3 & 2.2 & & \\
\hline Student & 129 & 100.0 & 0 & 0.0 & 0 & 0.0 & & \\
\hline Farmer & 98 & 98.0 & 1 & 1.0 & 1 & 1.0 & & \\
\hline Unemployed or retired & 12 & 100.0 & 0 & 0.0 & 0 & 0.0 & & \\
\hline \multicolumn{9}{|l|}{ BMI group } \\
\hline Underweight & 62 & 98.8 & 1 & 1.6 & 1 & 1.6 & \multirow[t]{5}{*}{10.1} & 0.26 \\
\hline Normal weight & 482 & 97.0 & 1 & 0.2 & 14 & 2.8 & & \\
\hline Overweight & 306 & 94.7 & 8 & 2.5 & 9 & 2.8 & & \\
\hline Obese & 148 & 94.8 & 4 & 2.6 & 4 & 2.6 & & \\
\hline Morbidly obese & 58 & 95.1 & 2 & 3.3 & 1 & 1.6 & & \\
\hline \multicolumn{9}{|l|}{ Blood pressure } \\
\hline Normotensive & 130 & 100.0 & 0 & 0.0 & 0 & 0.0 & \multirow[t]{3}{*}{14.9} & 0.02 \\
\hline Prehypertension & 497 & 96.9 & 6 & 1.2 & 10 & 1.9 & & \\
\hline Hypertension & 457 & 94.2 & 9 & 1.9 & 19 & 3.9 & & \\
\hline \multicolumn{9}{|l|}{ Family history of diabetes } \\
\hline Yes & 401 & 94.6 & 7 & 1.7 & 16 & 3.8 & \multirow[t]{2}{*}{4.6} & 0.10 \\
\hline No & 667 & 97.1 & 7 & 1.0 & 13 & 1.9 & & \\
\hline \multicolumn{9}{|l|}{ Alcohol consumption } \\
\hline Yes & 13 & 100.0 & 0 & 0.0 & 0 & 0.0 & 0.53 & 0.77 \\
\hline No & 1055 & 98.8 & 14 & 100.0 & 29 & 100.0 & & \\
\hline Cigarette smoking & & & & & & & & \\
\hline Yes & 102 & 96.2 & 1 & 0.9 & 3 & 2.8 & 0.12 & 0.9 \\
\hline No & 966 & 90.4 & 13 & 1.2 & 26 & 2.5 & & \\
\hline Most common tribes & & & & & & & & \\
\hline Gaaleen & 706 & 95.5 & 12 & 1.6 & 21 & 2.8 & 84.9 & 0.01 \\
\hline Rubatab & 163 & 96.4 & 1 & 0.6 & 5 & 3.0 & & \\
\hline Mairafab & 79 & 100.0 & 0 & 0.0 & 0 & 0.0 & & \\
\hline Manasir & 13 & 86.7 & 1 & 6.7 & 1 & 6.7 & & \\
\hline Ababda & 14 & 100.0 & 0 & 0.0 & 0 & 0.0 & & \\
\hline Shygia & 13 & 100.0 & 0 & 0.0 & 0 & 0.0 & & \\
\hline
\end{tabular}

a Totals in some categories are different as data were missing; ${ }^{b}$ Random blood glucose 9.4-11 mmol/L or fasting blood glucose 6.1-6.9 mmol/L; ${ }^{c}$ Fasting blood glucose $\geq$ $7 \mathrm{mmol} / \mathrm{L}$.

$B M I=$ body mass index $; I G T=$ Impaired glucose tolerance 
were from the Gaaleen tribe, which reflects the composition of the indigenous population in the study area and the $P$-value for this variable was significant; this is not surprising as the numbers of participants from other tribes were low.

The classic symptoms of diabetes, i.e. polydipsia, polyuria and fatigue, were not statistically significantly more prevalence in those with diabetes. However, loss of weight was a significant factor and was present in about half of those diagnosed with diabetes mellitus. Therefore, we assume that active screening is essential for case detection of diabetes mellitus.

This study had a number of limitations. The cross-sectional design might not show temporal relationships and thus the observed associations may not necessarily be causal. The study design effect can be assumed to be limited, as clusters of villages and individuals are somewhat similar (intraclass correlation) concerning ethnicity, age, sex, education and socioeconomic status.
The instrument used for measuring blood glucose (glucometer) was not the recognized gold standard for measuring blood glucose. The accuracy of glucometers has been challenged as there are multiple complexities involved in defining technical accuracy and a variety of factors can affect the results including operator technique, environmental exposure and patient factors (30). However, many screening studies have used a glucometer and reported its validity and specificity $(31,32)$. Due to logistic reasons we were unable to do other blood tests, e.g. oral glucose tolerance test, to increase the specificity. Some risk factors were difficult to quantify and in others the responses were unreliable, e.g. alcohol consumption, due to social and cultural constraints. We were also not able to distinguish the various types of diabetes mellitus in this study. Logistic regression analysis would have been better able to quantify the impact of each risk factor; however, the aim of our study was to determine the prevalence and associated risk factors rather than to evaluate scores for risk factors. Despite these limitations, this study is novel and is the first to report the prevalence of undiagnosed diabetes and associated risk factors in River Nile State. It therefore constitutes a database for further work.

\section{Conclusion}

The prevalence of undiagnosed diabetes in the rural communities of River Nile State was $2.6 \%$ and of glucose intolerance was $1.3 \%$. Active screening is recommended for individuals above 45 years, and those with hypertension or an unexplained loss of weight.

\section{Acknowledgements}

We are grateful to the participants of the study.

\section{Funding: None.}

Competing interests: None declared.

\section{References}

1. Danaei G, Finucane MM, Lu Y, Singh GM, Cowan MJ, Paciorek CJ, et al. Global Burden of Metabolic Risk Factors of Chronic Diseases Collaborating Group (Blood Glucose). National, regional, and global trends in fasting plasma glucose and diabetes prevalence since 1980: systematic analysis of health examination surveys and epidemiological studies with 370 country-years and 2.7 million participants. Lancet 2011; 2;378(9785):31-40.

2. Whiting DR, Guariguata L, Weil C, Shaw J. IDF diabetes atlas: global estimates of the prevalence of diabetes for 2011 and 2030. Diabetes Res Clin Pract. 2011 Dec;94(3):311-21. PMID:22079683

3. Honeycutt AA, Boyle JP, Broglio KR, Thompson TJ, Hoerger TJ, Geiss LS, et al. A dynamic Markov model for forecasting diabetes prevalence in the United States through 2050. Health Care Manag Sci. 2003 Aug;6(3):155-64. PMID:12943151

4. Boyle JP, Thompson TJ, Gregg EW, Barker LE, Williamson DF. Projection of the year 2050 burden of diabetes in the US adult population: dynamic modeling of incidence, mortality, and prediabetes prevalence. Popul Health Metr. 2010;8:29. PMID:20969750

5. Brinks R, Tamayo T, Kowall B, Rathmann W. Prevalence of type 2 diabetes in Germany in 2040: estimates from an epidemiological model. Eur J Epidemiol. 2012 Oct;27(10):791-7. PMID:22878939

6. Alsheikh-Ali AA, Omar MI, Raal FJ, Rashed W, Hamoui O, Kane A, et al. Cardiovascular risk factor burden in Africa and the Middle East: the Africa Middle East Cardiovascular Epidemiological (ACE) study. PLoS One. 2014;9(8):e102830. PMID:25090638
7. Boutayeb A, Lamlili ENM, Boutayeb W, Maamri A, Ziyyat A, Ramdani N. The rise of diabetes prevalence in the Arab region. Open J Epidemiology. 2012;2:55-60.

8. Diabetes atlas. 6th ed. Brussels: International Diabetes Federation; 2013. (http://www.idf.org/diabetesatlas, accessed 28 January 2015).

9. van Dieren S, Beulens JW, van der Schouw YT, Grobbee DE, Neal B. The global burden of diabetes and its complications: an emerging pandemic. Eur J Cardiovasc Prev Rehabil. 2010 May;17 Suppl 1:S3-8. PMID:20489418

10. Popkin BM, Adair LS, Ng SW. Global nutrition transition and the pandemic of obesity in developing countries. Nutr Rev. 2012 Jan;70(1):3-21. PMID:22221213

11. Mohan V, Seedat YK, Pradeepa R. The rising burden of diabetes and hypertension in southeast asian and african regions: need for effective strategies for prevention and control in primary health care settings. Int J Hypertens. 2013;2013:409083. PMID:23573413

12. King H, Aubert RE, Herman WH. Global burden of diabetes, 1995-2025: prevalence, numerical estimates, and projections. Diabetes Care. 1998 Sep;21(9):1414-31. PMID:9727886

13. American Diabetes Association. Implications of the United Kingdom Prospective Diabetes Study. Diabetes Care. 2000 Jan;23 Suppl 1:S27-31. PMID:12017673

14. Elbagir MN, Eltom MA, Elmahadi EM, Kadam IM, Berne C. A population-based study of the prevalence of diabetes and impaired glucose tolerance in adults in northern Sudan. Diabetes Care. 1996 Oct;19(10):1126-8. PMID:8886561 
15. The WHO STEPwise approach Surveillance of risk factors for non-communicable diseases. Geneva: World Health Organization ; 2011.

16. National Institutes of Health. Clinical guidelines on the identification, evaluation, and treatment of overweight and obesity in adults: the evidence report. Obes Res. 1998 Sep;6 Suppl 2:51S-209S. PMID:9813653

17. Report of the Expert committee on the Diagnosis and Classifications of Diabetes Mellitus. Diabetes Care. 2003;26 suppl.1:S5-20. PMID:12502614

18. Chobanian AV, Bakris GL, Black HR, Cushman WC, Green LA, Izzo JL Jr, et al.; Joint National Committee on Prevention, Detection, Evaluation, and Treatment of High Blood Pressure. National Heart, Lung, and Blood Institute; National High Blood Pressure Education Program Coordinating Committee. Seventh report of the Joint National Committee on Prevention, Detection, Evaluation, and Treatment of High Blood Pressure. Hypertension. 2003 Dec;42(6):1206-52. PMID:14656957

19. Abubakari ARLW, Lauder W, Jones MC, Kirk A, Agyemang C, Bhopal RS. Prevalence and time trends in diabetes and physical inactivity among adult West African populations: the epidemic has arrived. Public Health. 2009 Sep;123(9):602-14. PMID:19748643

20. Leiter LA, Barr A, Bélanger A, Lubin S, Ross SA, Tildesley HD, et al.; Diabetes Screening in Canada (DIASCAN) Study. Diabetes Screening in Canada (DIASCAN) Study: prevalence of undiagnosed diabetes and glucose intolerance in family physician of fices. Diabetes Care. 2001 Jun;24(6):1038-43. PMID:11375367

21. Herman WH, Ali MA, Aubert RE, Engelgau MM, Kenny SJ, Gunter EW, et al. Diabetes mellitus in Egypt: risk factors and prevalence. Diabet Med. 1995 Dec;12(12):1126-31. PMID:8750225

22. Tazi MA, Abir-Khalil S, Chaouki N, Cherqaoui S, Lahmouz F, Sraïri JE, et al. Prevalence of the main cardiovascular risk factors in Morocco: results of a National Survey, 2000. J Hypertens. 2003 May;21(5):897-903. PMID:12714863

23. Ramachandran A, Mary S, Yamuna A, Murugesan N, Snehalatha $C$. High prevalence of diabetes and cardiovascular risk factors associated with urbanization in India. Diabetes Care. 2008 May;31(5):893-8. PMID:18310309

24. Mbanya JC, Motala AA, Sobngwi E, Assah FK, Enoru ST. Diabetes in sub-Saharan Africa. Lancet. 2010 Jun 26;375(9733):225466. PMID:20609971

25. Opeodu OI, Adeyemi BF. Undiagnosed diabetes mellitus: a survey of dental outpatients in a tertiary hospital. Afr J Med Med Sci. 2013 Mar;42(1):39-45. PMID:23909093

26. Hadaegh F, Bozorgmanesh MR, Ghasemi A, Harati H, Saadat N, Azizi F. High prevalence of undiagnosed diabetes and abnormal glucose tolerance in the Iranian urban population: Tehran Lipid and Glucose Study. BMC Public Health. 2008;8:176. PMID:18501007

27. Tazi MA, Abir-Khalil S, Chaouki N, Cherqaoui S, Lahmouz F, Sraïri JE, et al. Prevalence of the main cardiovascular risk factors in Morocco: results of a National Survey, 2000. J Hypertens. 2003 May;21(5):897-903. PMID:12714863

28. Bouguerra R, Alberti H, Salem LB, Rayana CB, Atti JE, Gaigi S, et al. The global diabetes pandemic: the Tunisian experience. Eur J Clin Nutr. 2007 Feb;61(2):160-5. PMID:16900086

29. Abebe SM, Berhane Y, Worku A, Assefa A. Diabetes mellitus in North West Ethiopia: a community based study. BMC Public Health. 2014;14:97. PMID:24479725

30. Tonyushkina K, Nichols JH. Glucose meters: a review of technical challenges to obtaining accurate results. J Diabetes Sci Technol. 2009 Jul;3(4):971-80. PMID:20144348

31. Rathmann W, Haastert B, Icks A, Löwel H, Meisinger C, Holle $\mathrm{R}$, et al. High prevalence of undiagnosed diabetes mellitus in Southern Germany: target populations for efficient screening. The KORA survey 2000. Diabetologia. 2003 Feb;46(2):182-9. PMID:12627316

32. Al KhalafMM, Eid MM, Najjar HA, Alhajry KM, Doi SA, Thalib L. Screening for diabetes in Kuwait and evaluation of risk scores. East Mediterr Health J. 2010 Jul;16(7):725-31. PMID:20799528 